\title{
Research Paper: The Relations Between Behavioral Problems and Demographic Variables in Students With Visual Impairment
}

\author{
Sara Ghorbaninejad $^{1}$ (D), Firoozeh Sajedi ${ }^{* *}$ (D), Masoumeh Pourmohamadreza Tajrishi ${ }^{3}$ (D), Samaneh Hosseinzadeh ${ }^{4}$ (D) \\ 1. Psychology and Education of Exceptional Children, University of Social Welfare and Rehabilitation Sciences, Tehran, Iran. \\ 2. Pediatric Neurorehabilitation Research Center, University of Social Welfare and Rehabilitation Sciences, Tehran, Iran. \\ 3. Department of Psychology and Education of Exceptional Children, University of Social Welfare and Rehabilitation Sciences, Tehran, Iran. \\ 4. Department of Biostatistics, University of Social Welfare and Rehabilitation Sciences, Tehran, Iran.
}

\begin{tabular}{|l|l|l|l|l}
\hline $\begin{array}{c}\text { Use your device to scan } \\
\text { and read the article online }\end{array}$ & $\begin{array}{l}\text { Cftation: Ghorbaninejad S, Sajedi F, Pourmohamadreza Tajrishi M, Hosseinzadeh S. The Relations Between Behavioral } \\
\text { Problems and Demographic Variables in Students With Visual Impairment Iranian Rehabilitation Journal. 2020; 18(3):249-256. } \\
\text { http://dx.doi.org/10.32598/irj.18.3.260.1 }\end{array}$ \\
& dol'http://dx.doi.org/10.32598/irj.18.3.260.1
\end{tabular}

\section{Article info:}

Received: 11 Aug 2019

Accepted: 01 Jan 2020

Available Online: 01 Sep 2020

Keywords:

Visual injury, Behavioral problems, Age, Duration, Gender, Congenital, Hereditary

\section{ABSTRACT}

Objectives: The most distinctive group of people with sensory disabilities is those with visual impairment. This study aimed to evaluate the relationship between behavioral problems and demographic variables in students with visual impairment in the academic year of 2018-2019 in Tehran City, Iran.

Methods: This cross-sectional, descriptive, and analytical study was conducted on students with visual impairment studying in four schools of exceptional children at the elementary and high school levels. The research population was 400, and the sample size was estimated at 200 using Cochran's formula. The sampling was carried out using the random cluster sampling method, where the floors of the school were considered and visually-impaired students were selected randomly from each school based on the number of students. Demographic characteristics questionnaire and Rutter behavior evaluation questionnaire (teacher form) were used to collect data.

Results: The Mean \pm SD behavioral problems score was $12.9 \pm 10.7$. According to the results, there was a negative and significant correlation between the subscales of behavioral problems with age and duration of the impairment. A significant difference was found in the mean of behavioral problems of visually-impaired or blind children caused by accident with those with congenital and hereditary problems. The regression model showed a significant difference between male and female subjects in terms of behavioral problems in a short duration after the injury ( $\leq 5$ years).

Discussion: Given the relationship between behavioral problems with gender and duration of injury, it is recommended that interventions be carried out during the first few years of injury, especially for female individuals, to prevent or reduce the severity of behavioral problems.

\section{* Corresponding Author:}




\section{Highlights}

- Students with visual impairments experience more behavioral problems than normal students.

- There is a relationship between the duration of visual impairment and students' behavioral problems with visual impairment.

- Early intervention can reduce the behavioral problems of students with visual impairments.

\section{Plain Language Summary}

Severe behavioral problems among people with visual impairments are often called "challenging behaviors." For example, aggression towards others, defiant, screaming, or self-harm are some behaviors that may be challenging for the family and other careers and relatives. These behaviors can result in social isolation and deprivation from participation in routine social activities, making it difficult for people with severe behavioral problems to develop a dignified life situation. Therefore, this study aimed to evaluate the relationship between behavioral problems and demographic variables in students with visual impairments. The results showed a significant difference between behavioral problems and the duration of the injury.

\section{Introduction}

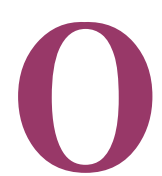

ne of the most vulnerable groups of people with sensory disabilities is visually-impaired and blind individuals [1]. Among the five senses of mankind, vision is one of the most important senses. Losing vision is associated with problems and complications that can affect the psychological and physical health of the individuals. Some of these problems include lack of personal independence, increased dependency on others, loss of function, little hope for the future, requiring help in performing daily activities, social isolation, behavioral problems, and lack of participation in social and religious activities [2].

Several studies have shown that children with vision problems formulate hostile schemas of the world in their minds based on their initial experiences, according to which they evaluate the intentions of others as hostile and react with courageous and aggressive behaviors. Blindness changes people's perception of the world and can cause various problems, including emotional-behavioral problems, incompatibility, inactivity, lack of interest in others, depression, and low self-concept. Visual impairment affects the cognitive and emotional development of blind individuals by limiting and changing their range of experiences and decreasing their movement level of environmental inhibition and interaction. Therefore, a limited opportunity that prevents the complete experience of the environment can create problems in the personal and emotional-behavioral growth of visually-impaired individuals [3].
Poor vision disrupts the development of an effective parent-child interaction. For instance, parents with their vision impairment cannot adapt to the negative emotions of their children or lack specific skills to communicate with and interact with them. As a result, their compatibility problems increase every day and are added to other behavioral problems $[4,5]$. These hostile behaviors occur because of various reasons, including the negative attitudes of the society toward people with vision impairment, the mental image of the society about their desperation and dependency, excessive support by parents [6], lack of receiving eye feedback for their behaviors, lack of model-making, lack of special visual skills, inability in finding a position and determining the place of the person [7]. To this list, we can add rejection and early negative reaction of parents to their children with vision impairment since their child does not encourage them with a smile and eye contact, and rejection by classmates since a student with vision impairment might ask a lot of questions or show inappropriate emotions [8].

Since behavioral problems in children with vision impairment cause several issues for teachers, school authorities, experts, and families, a considerable number of these students drop out of school and lose opportunities to learn various skills [9]. Besides, the presence of these behavioral problems results in negative emotions in children and misbehavior toward others. As such, children with vision impairment are rejected by their teachers and peers and lose popularity among them [7]. As pointed out by previous studies, different factors contribute to the behavioral problems of these individuals, one of which is 
age. The prevalence of behavioral problems in childhood and adolescence varies according to the stages of development in different countries as well as at different ages. In a study on pre-school age children in England, 7\% of the subjects had moderate to severe problems, whereas $15 \%$ had mild issues. In school-age children and during adolescence, the prevalence rates of problems have been reported to be $8.6 \%$ and $9 \%$, respectively [10].

Another issue related to the behavioral problems of these children is their gender. Several studies have demonstrated that the level of behavioral problems is higher in male children, compared to female individuals $[11,12]$.

As mentioned in previous studies, students with vision impairment have many behavioral issues. Nevertheless, the behavioral problems of students with vision impairment in Iran and the relevant factors are not known in this country due to the shortage of studies on this topic. Therefore, the present study was performed to fill this gap. On the other hand, students are a part of the society trained under the supervision of the educational system. The educational system always aims at providing material and spiritual conditions for the physical, emotional, and intellectual development of children. Therefore, the educational system as well as the family of students as the beneficiary group of the educational system expects decent, disciplined, consistent, and ethical graduation, and therefore, seeks compensation for any problem that hampers this process [13].

Behavioral problems play a determining role in the quality of life of students in educational, family, occupational, and social arenas. Therefore, conducting any research that could provide proper feedback to beneficiaries of education is valuable and important. If effective factors of behavioral problems are recognized by the researchers and specialists in the field of education, the relevant authorities make proper and precise planning to prevent and decrease these problems and implement timely interventions in this regard. So, the amount of financial and spiritual damages imposed on society and families by these issues could be decreased. Our findings could be exploited by organizations such as the Organization of Education of Exceptional Children, the General Welfare Organization of the country, and teachers and psychologists in the field of education. Therefore, the present study aimed to investigate the relationship between behavioral problems and demographic variables in students with visual impairment.

\section{Methods}

This cross-sectional, descriptive, and analytical research was performed on students with visual impairment studying in four schools of exceptional children at elementary and high school levels during the 2018-2019 academic year in Tehran, Iran. With regard to the study population of 400 , the sample size was estimated at 200 cases using Cochran's formula. The sampling was carried out by a random cluster sampling method, where the clusters were the desired schools and a proportional number of students were considered in each school due to an unequal number of students in the schools. The study data were collected using a researcher-made demographic characteristics questionnaire and Rutter behavioral evaluation questionnaire (teacher form). The demographic characteristics form collected age, gender, cause of vision impairment, birth rank, level of education of parents, the severity of blindness, and the economic status of families. They were completed based on the files of students.

The Rutter children's behavior questionnaire [14] was designed and introduced by this scholar to differentiate between normal children and those with behavioral problems. This 26-item tool is scored based on a 3-point Likert scale, and the cutoff point of the scale is 9, meaning that receiving a score of $\geq 9$ indicates disorders in children [14]. In the preliminary research by Rutter et al. on 91 children, the rate of agreement of the questionnaire with the diagnosis of a pediatric psychiatrist was $76.6 \%$, which was significant at the level of 0.01 . In another study by Rutter et al. [14], the agreement rate was reported at $61.5 \%$. In 1985 , the reliability of the questionnaire was reported as 0.85 by Rutter through a re-test within a 13-week interval. On the other hand, the reliability of the re-test for the teacher form was reported as 0.89 within a 2-month interval.

The questionnaire was first applied by Mahriar and Yousefi (1998) to evaluate the behavioral problems of Iranian children (Shiraz City, Iran). Considering the culture of the Iranian community, 6 items were added to the questionnaire, and the score of 13 (instead of 9 in the primary form of Rutter) was determined as the distinction between normal and abnormal students after applying changes to the questionnaire. In general, the questionnaire involves 5 different dimensions of behavioral disorders: aggression and hyperactivity, anxiety and depression, social incompatibility, antisocial behaviors, and attention deficit disorder. In the aforementioned research, 1600 first- to fifth-grade male and female elementary students aged 6-11 years were assessed in 
Shiraz City, Iran using the Rutter form (a 30-item questionnaire). In the mentioned study, the reliability of the test was estimated at 0.090 using a re-test. Mehriar and Yousefi calculated the validity of the questionnaire by using the correlation of each item's score with the total subscale score. The correlation coefficients were 0.44 in the subscale of aggression and hyperactivity, 0.68 in anxiety and depression, 0.63 in social maladaptation, 0.67 in antisocial behaviors, and 0.48 in attention deficit disorder. The reliability of the questionnaire was also obtained by calculating the Cronbach $\alpha$, which its coefficients were 0.53 on the subscale of aggression and hyperactivity, 0.77 on anxiety and depression, 0.73 on social maladaptation, 0.69 on antisocial behaviors, and 0.51 on attention deficit disorder.

In this study, we applied the Mann-Whitney $U$ and Kruskal-Wallis tests to evaluate the relationship between demographic variables and their behavioral problems and dimensions. Besides, the generalized linear model was fitted to the score of behavioral problems of stu- dents with vision impairment to assess the relationship between variables simultaneously.

\section{Results}

In total, 200 subjects were enrolled in the study, 56\% of whom were male, $73 \%$ were blind and the remaining participants were visually impaired. Also, 50\% of the students were the first child in the family. Moreover, $45 \%, 39 \%$, and $16 \%$ of the students had vision impairment due to hereditary, congenital, and accident causes, respectively. Regarding economic status, $78 \%$ of families had a moderate income. In addition, the mean age and duration of visual injury in students were 10.9 \pm 2.6 and $9.2 \pm 3.3$ years, respectively. Furthermore, the mean score of behavioral problems in the subjects was about $12.9 \pm 10.7$ (Table 1)

Besides, we exploited the Spearman correlation coefficient to evaluate the relationship between behavioral problems and their dimensions with age and duration of

Table 1. Mean score of behavioral problems, its subscales, and their correlation coefficients with age and duration of injury

\begin{tabular}{|cccc|}
\hline Behavioral Problem & Mean \pm SD & \multicolumn{2}{c}{ Correlation Coefficient } \\
\hline Aggression and hyperactivity & & Age & Duration of Injury \\
\hline Depression and anxiety & $2.31 \pm 1.99$ & $-0.340^{*}$ & $-0.427^{*}$ \\
\hline Social incompatibility & $2.90 \pm 2.89$ & $-0.338^{*}$ & $-0.470^{*}$ \\
\hline Antisocial behaviors & $2.37 \pm 2.19$ & $-0.208^{*}$ & $-0.360^{*}$ \\
\hline Attention deficit disorder & $1.16 \pm 1.83$ & $-0.290^{*}$ & $-0.339^{*}$ \\
\hline Behavioral problems & $2.82 \pm 1.93$ & -0.352 & $-0.423^{*}$ \\
\hline
\end{tabular}

$\mathrm{P}<0.05$ Пranian Rehabilitation \ournal

Table 2. Comparison of the mean score of behavioral problems and their dimensions based on the cause of damage

\begin{tabular}{|c|c|c|c|c|}
\hline \multirow{2}{*}{ Variable } & \multicolumn{3}{|c|}{ Mean \pm SD } & \multirow{2}{*}{$\mathbf{P}$} \\
\hline & Congenital & Hereditary & Accident & \\
\hline Aggression and hyperactivity & $2.21 \pm 1.90$ & $2 \pm 1.84$ & $3.43 \pm 2.28$ & 0.005 \\
\hline Depression and anxiety & $2.67 \pm 2.87$ & $2.46 \pm 2.79$ & $4.65 \pm 2.65$ & $<0.001$ \\
\hline Social incompatibility & $2.20 \pm 2.25$ & $2.12 \pm 2.04$ & $3.46 \pm 2.22$ & 0.004 \\
\hline Antisocial behaviors & $1.01 \pm 1.78$ & $0.89 \pm 1.49$ & $2.25 \pm 2.40$ & 0.003 \\
\hline Attention deficit disorder & $2.82 \pm 1.95$ & $2.45 \pm 1.78$ & $3.44 \pm 2.00$ & 0.007 \\
\hline Behavioral problems & $12.29 \pm 10.78$ & $11.07 \pm 9.59$ & $19.37 \pm 11.41$ & 0.001 \\
\hline
\end{tabular}


Table 3. Result of a generalized linear model of factors related to behavioral problems

\begin{tabular}{cccc}
\hline Variable (Base Level) & Value of Statistics & df & P \\
\hline Duration of injury ( $>5$ years) & 24.74 & 1 & $<0.001$ \\
Gender (female) & 7.84 & 1 & 0.005 \\
\hline Interaction of gender and duration of injury & 4.81 & Iranian Rehabilitation Dournal
\end{tabular}

injury, demonstrating a negative and significant correlation between aggression and hypertension, depression and anxiety, social incompatibility, antisocial behaviors, and attention deficit disorder with age and duration of injury $(\mathrm{P}<0.05)$. In other words, the score of behavioral problems and their dimensions decreased by aging and increased by the duration of injury (Table 1).

The mean scores of behavioral problems and their dimensions in three groups of students with congenital, hereditary, and accident injuries were compared with the Kruskal-Wallis test, demonstrating a significant difference in this regard $(\mathrm{P}<0.05)$ (Table 2). The Bonferroni correlation showed no significant difference in the mean scores of behavioral problems and their dimensions in two groups with congenital and hereditary injuries $(\mathrm{P}>0.05)$. Meanwhile, a significant difference was detected between those who have vision impairment due to accidents and those with congenital and hereditary impairments $(\mathrm{P}<0.05)$.

According to Mann-Whitney and Kruskal-Wallis tests, there were no significant differences in the mean score of behavioral problems and their dimensions at various levels of demographic characteristics such as birth rank, level of education of parents, economic status, and severity of blindness $(\mathrm{P}>0.05)$. The generalized linear model was applied to evaluate the effect of independent and auxiliary variables on behavioral problems. The injury duration was divided into two equal groups of below or above 5 years, and two variables of gender and duration of injury had a significant relationship with behavioral problems $(\mathrm{P}>0.05)$. However, the relationship between other demographic variables was not significant (Table 3 ).

As shown in Figure 1, the relation between gender and duration of injury was significant. Besides, Bonferroni correction demonstrated the mean behavioral problems of male participants with a duration of injury equal and higher than 5 years had no significant difference $(\mathrm{P}=0.085)$. Meanwhile, there was a significant difference in the mean behavioral problems of female participants with a duration of injury equal to 5 , compared to those above 5 years $(\mathrm{P}<0.05)$. Moreover, the mean behavioral problems in male and female individuals who were in the first few years of injury (equal or below 5 years) had a significant difference $(\mathrm{P}=0.045)$, whereas the mean behavioral problems in male and female subjects with a duration of injury above 5 years had no significant difference $(\mathrm{P}>0.05)$.

\section{Discussion}

According to the results of the present study, there was a negative and significant correlation between the subscales of aggression and hyperactivity, depression and anxiety, social compatibility, antisocial behaviors, and attention deficit disorder with age and duration of the injury. In other words, an increase in age and duration of injury resulted in a decreased score of behavioral problems and their dimensions. Some studies, including research studies by Wagner [15], Yildiz et al. [16], Barrera et al. [17], and Sacks et al. have yielded consistent results [18]. It could be expressed that the lack of visual cues in interpersonal relations.

In early childhood, visually-impaired people cannot see physical messages, also, they do not use other senses due to lack of adequate training. Therefore, their responses encounter problems, manifested as behavioral problems. However, these problems decrease by aging due to the education provided in schools and the relationship with peers [16]. Where children with visual impairment have

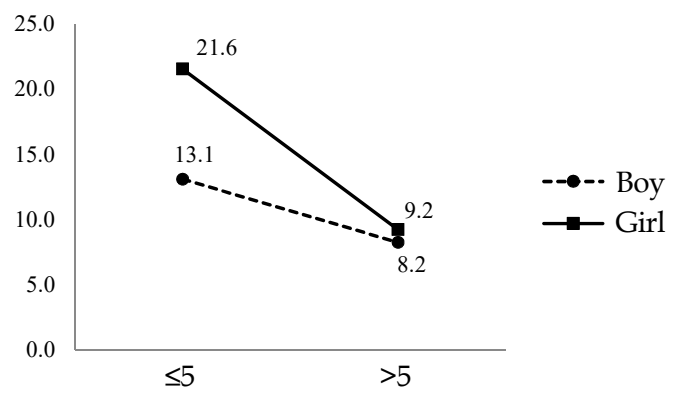

Iranian Rehabilitation Journa Figure 1. Mean score of behavioral problems of visually-impaired and blind children based on the gender and duration of injury 
difficulty acquiring adaptive behaviors through visual imaging, imitating, facial expressions, communication through look, and receiving feedback, they may not learn adaptive skills as well. But over time and with the improvement of other senses and more interaction with their friends in schools, they will have more chances to carry out positive behaviors.

Teaching adaptive skills to children with vision impairment improves their behavioral skills and abilities related to behavior management, corrects their maladaptive behaviors [17], and creates a good feeling for them in social situations [18]. Individual and identity development, job success, improvement of quality of life, physical well-being, mental health, self-esteem, autonomy, anxiety and depression reduction, failure, ability to cope with stress [19] and reducing a large part of aggressive behaviors, and emotional and social incompatibilities [15], increase in positive feedback and provision of more interactive opportunities will result in increased social sufficiency, self-esteem, and compatibility [15].

Besides, this study showed that the mean scores of behavioral problems and their subscales in blind and visually-impaired children caused by accident had a significant difference with two other congenital and hereditary causes and the scores of this group were higher, compared to the other two groups. To date, no research has directly addressed the relationship between behavioral problems and its dimensions with other demographic variables. Nevertheless, indirect and almost consistent studies on this topic include Hassell and Lamoureux [20], Brenner et al. [21], Lamoureux et al. [22], Finger et al. [23], and Sarabandi, Kamali and Mobaraki [1]. It can be mentioned that children with blindness due to congenital and hereditary issues adapt themselves to their conditions gradually, and since they have difficulty seeing from the beginning, they are more likely to accept their condition sooner and experience less anger. However, children who lose their vision due to an incident experience a greater shock and become aggressive, showing their problems from the outside [1].

\section{Conclusion}

One of the major drawbacks of this study was the limitation of results to visually-impaired and blind students. Therefore, a generalization of the results to other groups, including normal and exceptional children, must be carried out with caution. Besides, the Rutter teacher form was applied to measure behavioral problems. Therefore, only the viewpoints of teachers regarding the behavioral problems of children were assessed and more complete information could be attained if interviews were conducted with parents and children. It is recommended that similar studies be performed on other groups of exceptional students (mentally-retarded and deaf children) and their results be compared to our findings.

\section{Ethical Considerations}

\section{Compliance with ethical guidelines}

The informed consent was obtained from the parents before enrollment of the children in the research. The subjects were assured about the confidentiality of their information.

\section{Funding}

The present paper was extracted from the MA. thesis of the first author, Sara Ghorbaninejad, Department of Psychology and Education of Exceptional Children, University of Social Welfare and Rehabilitation Sciences.

\section{Authors' contributions}

Developing the study concept, design, and the definition of intellectual content: Sara Ghorbaninejad; Firouze Sajedi; Searching the literature: Sara ghorbaninejad, Masoume Pourmohamadreza-Tajrishi, and Firouze Sajedi; Conducting the study procedures and data collection: Sara Ghorbaninejad and Firouze Sajedi; Data analysis: Samane Hosseinzadeh and Sara Ghorbaninejad; Editing: Firouze Sajedi and Masoume Pourmohamadreza Tajrishi; Reviewing the manuscript and take responsibility for the integrity of the research as a whole from inception to published article: All authors.

\section{Conflict of interest}

The authors declared no conflict of interest.

\section{Acknowledgments}

We express our gratitude to the teachers of Tehran Province for assisting us in performing this research.

\section{References}

[1] Sarabandi A, Kamali M, Mobaraki H. The relationship between impaired visual function and quality of life of the blind. Research in Rehabilitation Sciences. 2013; 8(6):1015-23. [DOI: 10.22122/jrrs.v8i6.679] 
[2] Lam BL, Christ SL, Lee DJ, Zheng DD, Arheart KL. Reported visual impairment and risk of suicide: The 1986-1996 national health interview surveys. Archives of Ophthalmology. 2008; 126(7):975-80. [DOI:10.1001/archopht.126.7.975] [PMID] [PMCID]

[3] Malekitabar A, Khosh Konesh A, Khodabakhshi Koulaei A. [Comparison of self-concept and social adjustment in healthy and blind male persons (Persian)]. Zahedan Journal of Research in Medical Sciences. 2012; 13(suppl 1):33. https:// www.sid.ir/Fa/Journal/ViewPaper.aspx?id=154036

[4] Roch-Levecq AC. Production of basic emotions by children with congenital blindness: Evidence for the embodiment of theory of mind. British Journal of Developmental Psychology. 2006; 24(3):507-28. [DOI:10.1348/026151005X50663]

[5] Mostalami F. [The effectiveness of social skills training on increasing the self-confidence of blind girls in tehran, MSC in general psychology (Persian)]. [MSc. thesis]. Tehran: Alzahra University; 2002.

[6] Albert MM. Examining the social skills differences among at-risk youth diagnosed with learning disability, conduct disorder and serious emotional disturbance. Boston: Boston University; 2005.

[7] Kauffman JM, Hallahan DP, Pullen PC. Handbook of special education. $2^{\text {th }}$ ed. Abingdon: Routledge; 2017. [DOI:10.4324/9781315517698]

[8] Valås H. Learned helplessness and psychological adjustment: Effects of age, gender and academic achievement. Scandinavian Journal of Educational Research. 2001; 45(1):71-90. [DOI:10.1080/00313830020042689]

[9] Abaoud AA, Almalki NS. Characteristics of students with emotional/behavioral disorders: Perspectives of general education teachers in Saudi Arabia. Psychology. 2015; 6(5):525-32. [DOI:10.4236/psych.2015.65050]

[10] Gaddard N. Child and adolescent psychiatry. In: Wright P, Stern J, Phelan M, editors. Core psychiatry. $1^{\mathrm{ST}}$ ed. Manchester: W. B. Saunders. 2000

[11] Hoglund WL, Leadbeater BJ. The effects of family, school, and classroom ecologies on changes in children's social competence and emotional and behavioral problems in first grade. Developmental Psychology. 2004; 40(4):533-44. [DOI:10.1037/0012-1649.40.4.533] [PMID]

[12] Ortuno-Sierra J, Chocarro E, Fonseca-Pedrero E, I Riba SS, Muñiz J. The assessment of emotional and behavioural problems: Internal structure of the strengths and difficulties questionnaire. International Journal of Clinical and Health Psychology. 2015; 15(3):265-73. [DOI:10.1016/j.ijchp.2015.05.005] [PMID] [PMCID]

[13] Winiarski DA, Schechter JC, Brennan PA, Foster SL, Cunningham PB, Whitmore EA. Adolescent physiological and behavioral patterns of emotion dysregulation predict multisystemic therapy response. Journal of Emotional and Behavioral Disorders. 2017; 25(3):131-42. [DOI:10.1177/1063426616638315] [PMID] [PMCID]

[14] Rutter M. A children's behaviour questionnaire for completion by teachers: preliminary findings. Journal of Child Psychology and Psychiatry. 1967; 8(1):1-11. [DOI:10.1111/j.1469-7610.1967.tb02175.x]
[15] Wagner E. Development and implementation of a curriculum to develop social competence for students with visual impairments in Germany. Journal of Visual Impairment \& Blindness 2004; 98(11):703-10. [DOI:10.1177/014548 2X0409801105]

[16] Yildiz MA, Duy B. Improving empathy and communication skills of visually impaired early adolescents through a psycho-education program. Educational Sciences: Theory and Practice. 2013; 13(3):1470-6. [DOI: 10.12738/estp.2013.3.1607]

[17] Barrera Jr M, Biglan A, Taylor TK, Gunn BK, Smolkowski $\mathrm{K}$, Black C, et al. Early elementary school intervention to reduce conduct problems: A randomized trial with hispanic and non-hispanic children. Prevention Science. 2002; 3(2):8394. [DOI: 10.1023/a:1015443932331] [PMID]

[18] Sacks S, Wolffe KE. Teaching social skills to students with visual impairments: From theory to practice. Virginia: American Foundation for the Blind; 2006. https://books.google. $\mathrm{com} /$ books?id=QnqSVWNdumoC\&printsec $=$ frontcover\&so urce $=$ gbs_ge_summary_r\&cad $=0 \# \mathrm{v}=$ onepage $\& \mathrm{q} \& \mathrm{f}=$ false

[19] Sharifi Daramadi P. The Effect of social skills training based on cognitive- behavioral approach on psychological adjustment of blind male students. Psychology of Exceptional Persons. 2011; 1(1):45-66. https://jpe.atu.ac.ir/article_2025_ en.html

[20] Hassell J, Lamoureux EL, Keeffe JE. Impact of age related macular degeneration on quality of life. British Journal of Ophthalmology. 2006; 90(5):593-6. [DOI:10.1136/bjo.2005.086595] [PMID] [PMCID]

[21] Brenner MH, Curbow B, Javitt JC, Legro MW, Sommer A. Vision change and quality of life in the elderly: Response to cataract surgery and treatment of other chronic ocular conditions. Archives of Ophthalmology. 1993; 111(5):680-5. [DOI:10.1001/archopht.1993.01090050114040] [PMID]

[22] Lamoureux EL, Pallant JF, Pesudovs K, Tennant A, Rees $\mathrm{G}, \mathrm{O}^{\prime}$ Connor PM, et al. Assessing participation in daily living and the effectiveness of rehabiliation in age related macular degeneration patients using the impact of vision impairment scale. Ophthalmic Epidemiology. 2008; 15(2):105-13. [DOI:10.1080/09286580701840354] [PMID]

[23] Finger RP, Kupitz DG, Holz FG, Balasubramaniam B, Ramani RV, Lamoureux EL, et al. The impact of the severity of vision loss on vision-related quality of life in India: An evaluation of the IND-VFQ-33. Investigative Ophthalmology \& Visual Science. 2011; 52(9):6081-8. [DOI:10.1167/iovs.117388] [PMID] 
This Page Intentionally Left Blank 